\title{
Impacts of Feed-in Tariff and Metering Types on Electricity Consumption Efficiency in Australia
}

\author{
$\underline{\text { Omid Motlagh }}^{\text {a }}$, George Grozev a and Greg Foliente ${ }^{\text {a }}$ \\ ${ }^{a}$ CSIRO Land and Water, 37 Graham Rd., 3190 Highett, VIC, Australia \\ Email: omid.motlagh@csiro.au
}

\begin{abstract}
Small scale renewable energy technology mainly includes rooftop solar photovoltaic (PV) panels for electricity generation at household level. Solar feed-in tariff (FiT) is meant to encourage households to alleviate import from electricity grid especially during peak demand, via investment on on-site generation. We investigate the impact of FiT, net and gross metering types on household energy consumption, in Australia.

A macro level model is developed for New South Wales (NSW) using a recent Australian household energy consumption dataset. The results indicate that net metering is more effective than gross metering, in terms of curtailing electricity consumption. Additional micro level analysis is conducted for Queensland (QLD) and other states which also verify similar effects.

In the last four years the cost of production of solar panels has declined by 80 percent, which alongside high FiT would increase the number of prosumers. An immediate response is that most states have already reduced FiT to one third or less. However, further decline in technology cost and the advent of new technology are expected to lead to massive uptake. Today, more than 10 percent of Australians use solar power. The 8,000 rooftop solar systems in 2007 have increased to 1 million in 2013, a number first expected for 2030 (ABC, 2013). On the other hand, since the intermittent PV electricity is not fully reliable, the stable grid electricity has become more pricy. In Australia, average annual electricity price is now rising at 8\% (ABS, 2013). Accordingly, households opt to either invest more on renewable technologies or adapt to lowered consumption.
\end{abstract}

Statistics show average annual electricity consumption decline by 5.8\% since 2009 (AER, 2014). This reduction is at both households with or without renewable electricity technology (ABS, 2014b). An implication is that non-generating households now have to suffer from high price of grid electricity, while generating households have less difficulty. In fact high FiT would even make profit. The situation signifies the need for a minimal FiT that could still encourage sustainable uptake of the renewables.

In this article, we analyse and evaluate solar FiT in Australia since its introduction in 2008. Our focus goes on investigating the impacts of metering types (gross and net) with low and high FiTs on electricity efficiency behaviours in Australia, however regardless of Renewable Energy Target (RET) incentives and possible retail price-tariff structures. In gross metering $(\mathrm{GM})$, imported electric energy $\left(\mathrm{E}_{\mathrm{in}} \mathrm{kWh}\right)$ and exported energy $\left(\mathrm{E}_{\text {out }}\right.$ $\mathrm{kWh}$ ) are metered separately and respectively equal to total consumption and solar generation, while in net metering $(\mathrm{NM})$, the offset values are equal, i.e., $\mathrm{E}_{\text {out }}-\mathrm{E}_{\mathrm{in}}=$ generation minus consumption. Dwellings with no onsite electricity generation use non-generating meters (ngM). The notations, GM, NM, ngM, are used frequently in this article.

This study indicates that high FiT only encourages higher consumption and does not effectively alleviate demand from grid. This in particular applies to GM where FiT profit is more visible. In comparison, under high FiT, GM households tend to consume more electricity than NM households, while in general all generating households (whether GM or NM) consume more electricity than non-generating households. This could be further discussed with regards to the rebound effect. Another implication of this study is in line with maintaining low FiT. For example Victoria has reduced FiT per kWh from 60c to 25c and to 8c, from 2009 to 2014. The FiT currently offers minimum premium of 8c per kWh for excess electricity exported to the grid. Some electricity retailers may offer higher rates although not obligated to do so. The Essential Services Commission (ESC) has released a decision to adopt a minimum FiT of 6.2c per kWh from 2015 (FiT, 2014a). Other states have reduced FiT, capped generation capacity, or cut premiums.

Important Disclaimer:

CSIRO advises that the information contained in this publication comprises general statements based on scientific research. The reader is advised and needs to be aware that such information may be incomplete or unable to be used in any specific situation. No reliance or actions must therefore be made on that information without seeking prior expert professional, scientific and technical advice. To the extent permitted by law, CSIRO (including its employees and consultants) excludes all liability to any person for any consequences, including but not limited to all losses, damages, costs, expenses and any other compensation, arising directly or indirectly from using this publication (in part or in whole) and any information or material contained in it.

Keywords: Solar feed-in tariff, net metering, solar panel uptake 


\section{INTRODUCTION}

A feed-in-tariff (FiT) (Couture and Gagnon, 2010) is an incentive to encourage uptake of renewable energy technology including photovoltaic (PV) so that users alleviate import from grid. An optimized FiT facilitates smooth uptake of renewable technology and at the same time promotes energy management and efficiency behaviours among households. Reversely, a high FiT ends up with more prosumer emergence (CSIRO, 2013), who are less concerned with energy efficiency and bill saving, and rather view FiT a profit making incentive. An Australian study analysed PV electricity price in all states using economical models to determine the accurate unit price of grid-connected rooftop PV electricity in $\$ / \mathrm{kWh}$ throughout the year (Zahedi, 2009). Several configurations were considered depending on initial rebate and subsidies. For example, a case with $\$ 2 / \mathrm{W}$ setup cost would return $15 \mathrm{c} / \mathrm{kWh}$ worth of electricity in January. The estimated cost of generated electricity was then used to determine the base of FiT to justify the investment. A summary of recent estimations for setup cost (depending on capacity) across Australia is given in (SC, 2014). In China, Rigter and Vidican (2010) proposed a closed form equation that uses forecasts on future PV prices to derive an optimal FiT. King and Yu (2012) evaluated Taiwan's FiT scheme and Renewable Portfolio Standards (RPS), i.e., similar to Australian Renewable Energy Target (RET, 2014). A study in Ukraine, compared FiT against cost of energy production for different types of renewable energy. High FiT tariff and guaranteed access to grid were shown to be the main drivers toward green electricity production (Trypolska, 2012). However, excluding high FiT (due to its disadvantages), other studies showed a number of other drivers and motivational factors. These include both financial, e.g., insulation against rising energy prices, reduced outgoings in retirement, as well as non-financial factors, e.g., independence and self-sufficiency, resilience against outages, etc. The only study in favour of high FiT is about Thailand believing that high FiT laws create income opportunities for rural communities and offer significant potential to reduce imports of oil and coal (Greacen et al., 2003). However, as mentioned, most of the literature is against high FiT in particular in Australia (Martin and Rice, 2013) believing that low FiT still satisfies sustainable growth of renewable energy market, without disadvantages. Net metering scheme is supported in other literature to work along with low FiT. At last, the FiT itself can evolve to other measures, from social and environmental perspectives. For example, Eyre (2013) extended the concept of FiTs from power generation to energy saving called ESFiT. While FiT is a guaranteed price paid for each unit of energy produced, ESFiT defines a unit of saved energy, then pays a value depending on the public benefit and its worth. As an effective strategy, metering types (NM and GM) could play a role. In Australia, GM was first introduced in NSW in 2009, where costumers enjoyed FiT as high as $\$ 0.60$ to $\$ 0.68$ per $\mathrm{kWh}$. However, only a year later (October 2010), the FiT was cut down to $\$ 0.20$, the lowest across Australia (AAP, 2010), on the realization of the faulty financial model with an over generous FiT (Martin and Rice, 2013). The NSW model had even triggered a movement among other PV owners in other states demanding for a national gross metering scheme. For example, 23000 households signed an online petition for a national gross feed in tariff (FiT, 2009). However by cutting FiT from higher than retail price (constant profit) to lower (constant loss), gross metering had to be replaced with net metering for the sake of social welfare. Therefore the trend is now toward net metering (NM) which makes a better balance between PV uptake (therefore PV panel imports) and expansion of Australian production (SFF, 2009). Analysis shows that under low FiT net metering is still profitable, especially when household electricity bill is taken into account (Poullikkas, 2013). High FiT allows for high profit leading to higher consumption (a rebound effect). Net metering is all about bill saving, efficient consumption, and occasionally profit making.

\section{DATA EXPLORATION}

A data driven methodology is implemented to analyse NM and GM under high and low FiT. The Australian Bureau of Statistics (ABS) published a public business survey of residential electricity distribution (ABS, 2014), based on experimental estimates in all Australian states, for 2010, 2011, and partially for 2012. The dataset includes electricity imported $\left(\mathrm{E}_{\mathrm{in}}\right)$ as well as electricity exported $\left(\mathrm{E}_{\text {out }}\right)$ at residential meters. For dwellings with solar generation, in most states net import-export electricity is measured using a single meter. In NSW however, import and export electricity are measured separately. The summary of the data at state level is given in Table 1 which accordingly reveals several explicit facts especially about dwellings with GM and ngM. NM dwellings however require further processing. First, the supply data (supply mean $(\mathrm{kWh})$ in Table 1 ) shows that average electricity imported by all NM, GM, and ngM classes has declined by almost 3\%, 9\%, 6\% (from 2010 to 2011 ), and by $5 \%, 1 \%, 6 \%$ (from 2011 to 2012 ), respectively. Imported energy is directly proportional to electricity consumption at GM and ngM households. The fact that ngM households reduced consumption steadily by $6 \%$ per year indicates overall tendency towards low usage, regardless of generating solar electricity. GM consumption has less reduction in the second year, which implies that the high return from FiT in 2010 lead to rebound effect in 2011. Reversely, NM households seems to have consumed less energy in the second year (i.e., from $3 \%$ to $5 \%$ reduction), although imported energy is not directly related to household consumption. However, this is verified by main distributors in NSW that customers on NM try to cut consumption more often than GM customers (GE, 2014). Another fact is about uptake of solar technology within two years, from 2010 to 2012. 
Since on average, similar technology has been used regardless of NM or GM metering, the total number of all generating meters (whether GM or NM) reveals 89\% and 24\% annual uptake in 2010-11 and 2011-12, respectively. However, a closer look shows the effect is only on GM households, as solar uptake at NM households (122\%) is much higher than GM households (2\%) in 2011. The considerable decline in solar uptake at GM households (i.e., from $75 \%$ to $2 \%$ ) is a response to reduced FiT. However, NM households sustain contribution to solar uptake. It is explicit that in general NM leads to sustainable consumption, alongside high uptake rate. At last, the higher average consumption at generating dwellings (compared to non-generating dwellings links with the rebound effect. For instance, a comparison between GM and ngM dwellings shows $12.6 \%$ higher consumption averaged over 3 million households in 2010-2012.

Table 1. Electricity consumption at generating and non-generating dwellings, NSW, 2010-2012 calendar years.

\begin{tabular}{|c|c|c|c|c|c|c|c|c|c|c|}
\hline \multirow{3}{*}{\multicolumn{2}{|c|}{$\begin{array}{l}\text { Dwellings } \\
\text { Metering standard } \\
\text { Year }\end{array}$}} & \multicolumn{6}{|c|}{ Dwellings with electricity generation capabilities } & \multirow{2}{*}{\multicolumn{3}{|c|}{$\begin{array}{l}\text { without electricity generation } \\
\text { non-generation Metering (ngM) }\end{array}$}} \\
\hline & & \multicolumn{3}{|c|}{ Net Metering (NM) } & \multicolumn{3}{|c|}{ Gross Metering (GM) } & & & \\
\hline & & 2010 & 2011 & 2012 & 2010 & 2011 & 2012 & 2010 & 2011 & 2012 \\
\hline Nun & er of residential electricity meters & 7,286 & 21,100 & 46,834 & 50,526 & 88,406 & 89,920 & $2,884,934$ & $2,853,827$ & $2,848,103$ \\
\hline Pro & rtion of electricity meters (\%) & 0 & 1 & 2 & 2 & 3 & 3 & 98 & 96 & 95 \\
\hline \multicolumn{11}{|c|}{ Electricity supplied to dwellings } \\
\hline \multicolumn{2}{|c|}{ Supply mean (kWh) } & 6,667 & 6,458 & 6,127 & 7,716 & 7,018 & 6,950 & 6,815 & 6,418 & 6,038 \\
\hline Q1 & Lowest quintile (kWh) & 2,034 & 1,928 & 1,509 & 2,634 & 2,409 & 2,336 & 1,734 & 1,596 & 1,502 \\
\hline Q2 & Second quintile $(\mathrm{kWh})$ & 3,773 & 3,787 & 3,157 & 4,804 & 4,333 & 4,190 & 3,876 & 3,598 & 3,342 \\
\hline Q3 & Third quintile (kWh) & 5,439 & 5,440 & 4,797 & 6,715 & 6,038 & 5,814 & 5,738 & 5,355 & 4,971 \\
\hline Q4 & Fourth quintile (kWh) & 7,737 & 7,571 & 7,070 & 9,131 & 8,232 & 7,971 & 8,164 & 7,679 & 7,159 \\
\hline Q5 & Highest quintile (kWh) & 14,321 & 13,546 & 14,091 & 15,292 & 14,073 & 14,435 & 14,560 & 13,862 & 13,215 \\
\hline \multicolumn{11}{|c|}{ Electricity supplied back to grid } \\
\hline \multicolumn{2}{|c|}{ Supply mean $(\mathrm{kWh})$} & 736 & 711 & $\mathrm{np}$ & 829 & 1,969 & $\mathrm{np}$ & na & na & na \\
\hline Q1 & Lowest quintile (kWh) & 89 & 111 & $\mathrm{np}$ & 81 & 642 & $\mathrm{np}$ & na & na & na \\
\hline Q2 & Second quintile (kWh) & 354 & 336 & np & 304 & 1,119 & np & na & na & na \\
\hline Q3 & Third quintile (kWh) & 614 & 551 & np & 612 & 1,502 & $\mathrm{np}$ & na & na & na \\
\hline Q4 & Fourth quintile (kWh) & 867 & 828 & np & 963 & 2,043 & $\mathrm{np}$ & na & na & na \\
\hline Q5 & Highest quintile (kWh) & 1,756 & 1,728 & $\mathrm{np}$ & 2,182 & 4,531 & $\mathrm{np}$ & na & na & na \\
\hline
\end{tabular}

\section{METHODS AND RESULTS}

NM consumption and solar generation is not as explicit as GM. A system of equations (1) is realized for net metering for all five quintiles $(Q)$ within the dataset, where $(d)$ represents dwellings demand in $\mathrm{kW},(g)$ is renewable energy presumably from solar PVs $(k W),(I)$ is hours or number of instances with $g>d$, and $(J)$ is number of instances with $d>g$. Eq. (1) could be rewritten in form of (2), given the total number of instances in one year $N$ equals to total hours in one year (i.e., $24 \times 365$ ), so that $g$ and $d$ would be in $k W$. Accordingly, there is an indication of average values of generation, demand, and number of instances where either transient generation or demand gets greater than the other, i.e., $I$ (hours) and $J$ (hours), respectively. On the other hand, for gross metering, Eq. (1-2) transform to (3) due to direct import and export of electricity. The last formulation is about non-generating metering where in absence of on-site generation, a single equation (4) describes the demand. The system is then analysed where index (Q) represents each of the quintiles, NM, GM, and ngM represent related metering standards, as formulated in Eq. (1-2), (3), and (4), respectively.

$$
\begin{aligned}
& \left\{\begin{array}{l}
\sum_{i=1}^{I}(d-g)_{i}=E_{\text {in }} \\
\sum_{j=1}^{J}(g-d)_{j}=E_{\text {out }}
\end{array}\right. \\
& \left\{\begin{array} { l } 
{ \sum _ { n = 1 } ^ { N } ( d ) _ { n } = E _ { \text { in } } } \\
{ \sum _ { n = 1 } ^ { N } ( g ) _ { n } = E _ { \text { out } } }
\end{array} \Rightarrow \left\{\begin{array}{l}
\bar{d}=E_{\text {in }} / N \\
\bar{g}=E_{\text {out }} / N
\end{array}\right.\right. \\
& \left\{\begin{array}{l}
D: \bar{d}_{G M\left\{Q_{q}\right\}} \approx \bar{d}_{N M\left\{Q_{q}\right\}} \\
G: \bar{g}_{G M\left\{Q_{q}\right\}} \approx \bar{g}_{N M\left\{Q_{q}\right\}} \\
O:(\overline{d-g})_{N M\left\{Q_{q}\right\}} \approx(\overline{d-g})_{G M\left\{Q_{q}\right\}}
\end{array}\right.
\end{aligned}
$$$$
\sum_{n=1}^{N}(d)_{n}=E_{\text {in }} \Rightarrow \bar{d}=E_{\text {in }} / N
$$

Solving Eq. (2) for NM dwellings, the values of $I_{N M}, J_{N M}$, and average of $\pm(g-d)_{N M}$ will be obtained. On the other hand, Eq. (3) directly reveals values of average $d_{G M}$ and $g_{G M}$ for GM households. Now, let us make an assumption about households within quintile $Q_{q}$ as a subset of the entire NM sample set $\left(Q_{q} \subset \mathrm{NM}, q=1 \ldots 5\right)$ having similar demand and generation behaviour as households belonging to corresponding quintiles of the GM sample set (5). The evidence is that all samples have been pulled out of the same population (NSW) with only different metering protocols. We employ a linear regression based on the supervised learning in neural networks. A single layer perceptron is formed with nodes $D$ representing demand and $G$ generation at input, and node $O$ representing their offset at output. The network is first loaded with known values $\{D, G, O\}$, i.e., $D$ and $G$ from $\mathrm{GM}$, and $O$ from NM (left hand side values in (5)). The trained system is then used to guess on unknown values of $D$ and $G$ from NM, through deduction from known value of $O$ from GM (right hand side values in (5)). 
Table 2. NSW representing main Australian demographics (2006-2009)

ABS census (ABS, 2014).

\begin{tabular}{|c|c|c|c|c|c|}
\hline Demographics & Australia & Newcastle & Demographics & Australia & Newcastle \\
\hline \multicolumn{3}{|l|}{ Age: } & Median family income: & 1171 & 1132 \\
\hline $0-4$ & 0.06 & 0.06 & & & \\
\hline $5-14$ & 0.14 & 0.11 & Occupied private dwelling: & & \\
\hline $15-24$ & 0.14 & 0.15 & Separate house & 0.75 & 0.73 \\
\hline $25-54$ & 0.42 & 0.41 & Semi-detached house & 0.09 & 0.11 \\
\hline $55-64$ & 0.11 & 0.1 & Flat, unit or apartment & 0.14 & 0.15 \\
\hline \multirow[t]{2}{*}{$65+$} & 0.13 & 0.16 & & & \\
\hline & & & Tenure: & & \\
\hline Family characteristics: & & & Fully owned or being purchased & 0.65 & 0.61 \\
\hline Couple families with children & 0.45 & 0.4 & Rented & 0.27 & 0.32 \\
\hline Couple families without children & 0.37 & 0.38 & & & \\
\hline One parent families & 0.16 & 0.19 & Internet connections: & 0.58 & 0.53 \\
\hline
\end{tabular}

\subsection{NSW Renewable Electricity Generation and Consumption}

New South Wales (NSW) hosts one third of the Australian population; and is well representing the demographics. Table 2 shows Newcastle city located in east NSW, against Australia (EA, 2014). In particular the related dataset of this study (NM and GM) are from NSW. We apply the process on the three household sectors (NM, GM, ngM) of NSW dataset in Table 1, so that instead of $\mathrm{E}_{\text {in }}$ and $\mathrm{E}_{\text {out }}$, average demand $(d)$ and renewable generation $(g)$ are obtained (Table 3). Additionally, the expected values of $I_{N M}$ (hours without renewable energy generation) and $J_{N M}$, (hours of renewable energy generation) is included. To estimate unpublished NM and GM values of $\mathrm{E}_{\text {out }}$ for year 2012 we estimate $(g-d)_{N M}$ and $(g-d)_{G M}$ for year 2012, and with the available values of $E_{i n}, N M$ and $G M$ values of $E_{\text {out }}$. At the first glance, Table 3 reveals the same fact that electricity demand at households with generation capability is on average $10-20 \%$ higher than demand at households without generation capability. This is attributed to psychological factors mainly household's confidence in its electricity generation capability leading to lavish consumption. Second, the ratio of GM demand over NM demand has reduced from $>1$ in 2010, to $<1$ in 2011. This verifies the fact that in 2010, GM households relatively consumed more energy due to higher FiT $=20-68 \mathrm{c}$ compared to NM FiT which was often in effect equal to electricity price (FiT $\leq 26 \mathrm{c}$ ). This in particular relates to GM installations prior to October 2010 with all connection enjoying the $\sim 60 \mathrm{c}$ rate. However, 2011 values, and expected values for 2012 (underlined values in Table 3) indicate that new households (and those dragged from 2010 to 2011) changed trend due to FiT changes in favour of net metering. After April 2011, with new FiT, net metering is preferred by most new customers, reported by a NSW distributor (GE, 2014). Investigation on $I$ (hours of $d>g$ ) and $J$ (hours of $g>d$ ) reveal overall demand and generation profiles. However, this is a rough estimate and may not reflect exact hours. A limitation is about the assumption for $|g-d|_{i}=|d-g|_{j}=|g-d|_{N}$ which might be far from the reality. Another limitation over time dimension is about unknown sequence of instances $i \in I$ and $j \in J$. From another perspective, $J$ values can be used to infer solar capacity. For example, in 2010 the NM- $Q_{l}$ households had on average $J=338$ hours of $g>d$ ( $\sim 1$ hour per day), while $Q_{5}$ households had $\sim 3$ hours of $g>d$ per day. With equal average hours of solar radiation, it seems that $J$ could reflect the size of solar panels $S_{Q_{q}}(\mathrm{~kW})$ used on average by each quintile (6). Further micro analysis is needed to obtain coefficient $\gamma$, e.g., Residential Building Electricity Efficiency (RBEE) dataset of individual households (Ambrose et al., 2013).

$S_{Q_{q}} \propto J_{Q_{q}}$

\subsection{NSW, a Top-Down Review}

To obtain NM demand and generation values in Table 3 we assumed that $Q_{1}-Q_{5}$ households in terms of demand match with $Q_{I}-Q_{5}$ households in terms of generation. This assumption is controversial as it may not apply to many cases, e.g., dwellings with high demand but low generation. Therefore, in this section, we repeat the analysis for individual NSW statistical areas level 2 (SA2) (ABS, 2014a), which eliminates the previous assumption for quintiles. Fortunately, in addition to the data summary (as shown in Table 1), the ABS dataset also includes $\mathrm{E}_{\text {in }}$ and $\mathrm{E}_{\text {out }}$ down to SA2 levels for NM, GM, and ngM dwellings, and for all Australian territories. We use these values to directly calculate ngM demand, and GM demand and generation. Values of NM demand and generation are inferred indirectly using similar neural inference mechanism. Fig. 1 shows the method of extracting these values from known $\mathrm{GM}$ and NM, $\mathrm{E}_{\text {in }}$ and $\mathrm{E}_{\text {out. }}$. Given the fact that all generating dwellings within the same SA2 (i.e., most likely within similar dominant climate zone), have similar solar generation on average, the difference between electricity demand is inferred using neural regression, with known values of $d_{G M}, g_{G M}$, and $(d-g)_{N M}$. As a result, Eq. (7-8) show ratios of $d_{G M} / d_{N M}$ and $g_{G M} / g_{N M}$ respectively for years 2010 and 2011, averaged over nearly $400 \mathrm{SA} 2 \mathrm{~s}$. The results show that $20 \%$ extra $d_{G M}$ in 2010 has reduced to comparable value of $d_{N M}$ in 2011. The ratios of $d_{G M} / d_{N M}$ in (7) and (8) are shown for all SAs in Fig. 2 (a) and (b), respectively. 


$$
\text { 2010: }\left\{\begin{array}{c}
d_{G M} / d_{N M}=1.189 \cong 1.2 \\
g_{G M} / g_{N M}=0.987 \cong 1
\end{array}\right.
$$

$$
\text { 2011: }\left\{\begin{array}{l}
d_{G M} / d_{N M}=0.962 \cong 1 \\
g_{G M} / g_{N M}=1.021 \cong 1
\end{array}\right.
$$

Table 3. NSW, consumption and domestic generation. GM and ngM demand is directly imported from grid. NM

\begin{tabular}{|c|c|c|c|c|c|c|c|c|c|c|c|c|c|c|c|c|}
\hline \multirow{3}{*}{\multicolumn{2}{|c|}{$\begin{array}{l}\text { Dwellings } \\
\text { Metering standard } \\
\text { Year }\end{array}$}} & \multicolumn{11}{|c|}{ Dwellings with electricity generation capabilities } & & \multirow{2}{*}{\multicolumn{3}{|c|}{$\begin{array}{l}\text { without solar generation } \\
\text { non-generation Metering }\end{array}$}} \\
\hline & & \multicolumn{6}{|c|}{ Net Metering (NM) } & \multicolumn{5}{|c|}{ Gross Metering (GM) } & & & & \\
\hline & & 2010 & & 2011 & & 2012 & & 2010 & & 2011 & & 2012 & & 2010 & 2011 & 2012 \\
\hline \multirow{2}{*}{\multicolumn{2}{|c|}{$\begin{array}{l}\text { Average dwellings demand } \\
\text { mean }(\mathrm{kW})\end{array}$}} & & I (h) & & I (h) & & I (h) & & I (h) & & I (h) & & I (h) & & & \\
\hline & & 0.7729 & 7793 & 0.8750 & 7007 & $\underline{0.8465}$ & 5507 & 0.881 & 7910 & 0.801 & 6841 & 0.793 & 5236 & 0.778 & 0.733 & 0.689 \\
\hline Q1 & Lowest quintile $(\mathrm{kW})$ & 0.2321 & 8422 & 0.2802 & 6951 & 0.2648 & 2775 & 0.301 & 8499 & 0.275 & 6917 & 0.267 & 2756 & 0.198 & 0.182 & 0.171 \\
\hline Q2 & Second quintile (kW) & 0.4255 & 8091 & 0.5200 & 7051 & 0.4903 & 4561 & 0.548 & 8239 & 0.495 & 6962 & 0.478 & 4417 & 0.442 & 0.411 & 0.382 \\
\hline Q3 & Third quintile (kW) & 0.6218 & 7862 & 0.7272 & 7107 & $\underline{0.6877}$ & 5526 & 0.767 & 8028 & 0.689 & 7015 & 0.664 & 5361 & 0.655 & 0.611 & 0.567 \\
\hline Q4 & Fourth quintile $(\mathrm{kW})$ & 0.8958 & 7790 & 0.9993 & 7124 & $\underline{0.9530}$ & 5857 & 1.042 & 7924 & 0.940 & 7018 & 0.910 & 5675 & 0.932 & 0.877 & 0.817 \\
\hline Q5 & Highest quintile $(\mathrm{kW})$ & 1.6847 & 7627 & 1.8419 & 6911 & $\underline{1.8361}$ & 5731 & 1.746 & 7666 & 1.607 & 6627 & 1.648 & 5303 & 1.662 & 1.582 & 1.509 \\
\hline \multirow{2}{*}{\multicolumn{2}{|c|}{$\begin{array}{l}\text { Average dwellings generation } \\
\text { mean }(\mathrm{kW})\end{array}$}} & & $\mathrm{J}(\mathrm{h})$ & & $\mathrm{J}(\mathrm{h})$ & & $\mathrm{J}(\mathrm{h})$ & & $\mathrm{J}(\mathrm{h})$ & & $\mathrm{J}(\mathrm{h})$ & & $\mathrm{J}(\mathrm{h})$ & & & \\
\hline & & 0.0959 & 967 & 0.219 & 1753 & $\underline{0.5000}$ & 3253 & 0.095 & 850 & 0.225 & 1919 & $\underline{0.534}$ & 3524 & na & na & na \\
\hline Q1 & Lowest quintile $(\mathrm{kW})$ & 0.0093 & 338 & 0.0729 & 1809 & $\underline{0.5710}$ & 5985 & 0.009 & 261 & 0.073 & 1843 & $\underline{0.581}$ & 6004 & na & na & na \\
\hline Q2 & Second quintile $(\mathrm{kW})$ & 0.0352 & 669 & 0.1261 & 1709 & $\underline{0.4515}$ & 4199 & 0.035 & 521 & 0.128 & 1798 & $\underline{0.470}$ & 4343 & na & na & na \\
\hline Q3 & Third quintile (kW) & 0.0711 & 898 & 0.1691 & 1653 & $\underline{0.4024}$ & 3234 & 0.070 & 732 & 0.171 & 1745 & $\underline{0.421}$ & 3399 & na & na & na \\
\hline Q4 & Fourth quintile $(\mathrm{kW})$ & 0.1116 & 970 & 0.2296 & 1636 & $\underline{0.4724}$ & 2903 & 0.110 & 836 & 0.233 & 1742 & $\underline{0.495}$ & 3085 & na & na & na \\
\hline Q5 & Highest quintile $(\mathrm{kW})$ & 0.2503 & 1133 & 0.4928 & 1849 & $\underline{0.9702}$ & 3029 & 0.249 & 1094 & 0.517 & 2133 & 1.074 & 3457 & na & na & na \\
\hline
\end{tabular}
demand could be imported from grid or from PV. Underlined values show unpublished values for 2012.

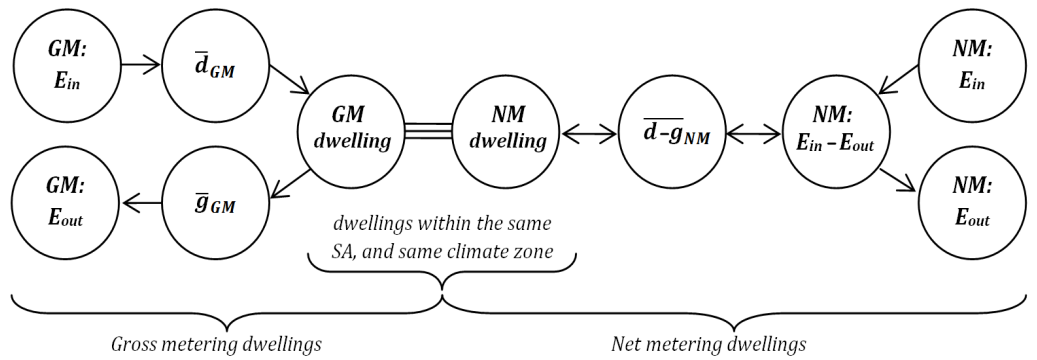

\subsection{QLD, a Bottom-Up Review}

Residential Building Electricity Efficiency (RBEE) is a nationwide research project for analysis of energy efficiency behaviours, consumption, solar generation, and other characteristics at individual dwellings, for a wide range of dwelling typologies, household types, and occupancy patterns. Among catchment areas, south east Queensland (SEQ) has the closest characteristics to both states of QLD and NSW, by population, demographics, and climate zone. The time series consumption and generation data, i.e., at 30 min resolution, is available for tens of non-generating as well as generating dwellings, from November 2012 to February 2013. At the first glance, average hourly electricity demand is measured at $\simeq 0.79 \mathrm{~kW}$ at non-generating dwellings, and $\simeq 0.87 \mathrm{~kW}$ at generating dwellings (in 2012). The difference shows $\simeq 10.1 \%$ higher consumption at generating dwellings. Similarly, macro level analysis suggests more accurate value of $12.6 \%$.

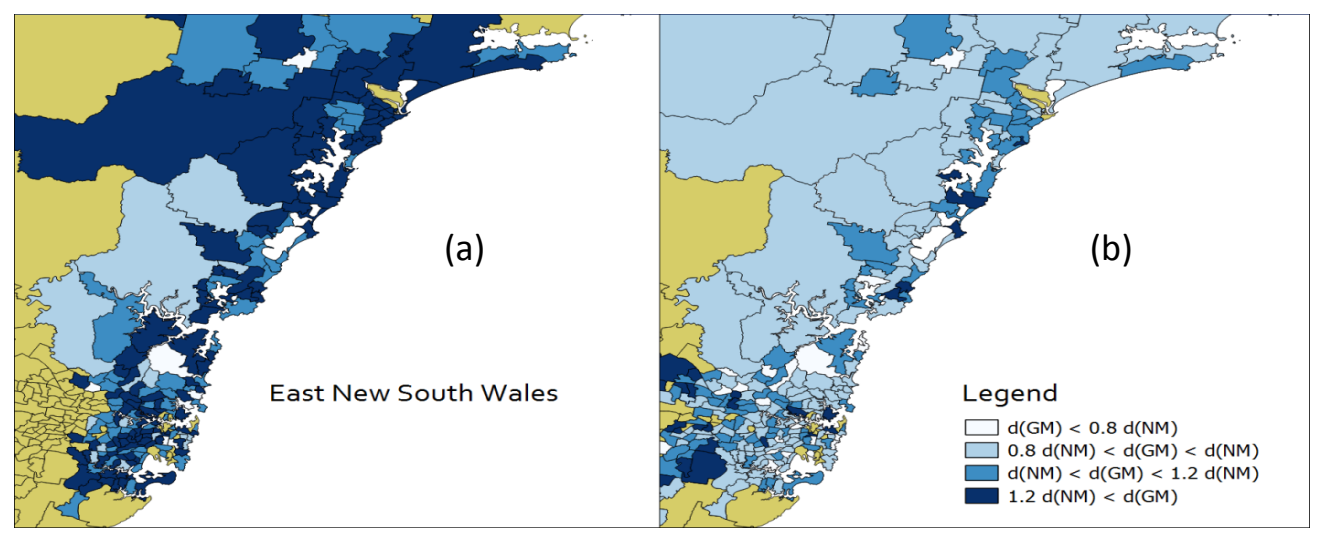

Figure 2.

$d_{G M} / d_{N M}$ in $\mathrm{SA}_{2}$ in NSW. (a) in $2010, d_{G M}$ is $20 \%$ higher than $d_{N M}$, (b) in $2011, d_{G M}$ is close to $d_{N M}$.

For generating dwellings, the hourly solar generation is averaged at $0.45 \mathrm{~kW}$, which accounts for $\simeq 52 \%$ of household hourly demand. Knowing that QLD practices NM, this high proportion signifies the effectiveness of NM. On the other hand, we obtained $\mathrm{d}_{\mathrm{GM}} / \mathrm{d}_{\mathrm{ngM}}=12.6 \%$ (in $2010-2012 \mathrm{NSW}$ ), while here $\mathrm{d}_{\mathrm{NM}} / \mathrm{d}_{\mathrm{ngM}}=10.1 \%$ is obtained (in 2012 in QLD). And since on average both states had almost similar FiTs over the given periods, i.e., QLD FiT $=44 \mathrm{c}$, and NSW $\mathrm{FiT}=(60+20) / 2=40 \mathrm{c}$, the ratio of $\mathrm{d}_{\mathrm{GM}} / \mathrm{d}_{\mathrm{NM}}$ could be obtained from 
$\left(\mathrm{d}_{\mathrm{GM}} / \mathrm{d}_{\mathrm{ngM}}\right) /\left(\mathrm{d}_{\mathrm{NM}} / \mathrm{d}_{\mathrm{ngM}}\right)=12.6 / 10.1 \simeq 1.25$. In other words, generating dwellings in QLD would have consumed $25 \%$ more electricity under GM. It is apparent from both macro and micro analysis that, given the FiT circumstances, GM households simply consume more electricity than NM households, while on average they use similar solar technology, and receive similar solar radiation. A positive feedback is then made by higher investment on PV technology in quest for higher return from FiT which in turn entails unleashed PV uptake. This reinforcing cycle could be best harnessed with lowered (minimised) FiT, while the reducing cost of technology sustains solar uptake.

\section{OTHER VIEWPOINTS}

We showed that net metering leads households towards energy efficient behaviours. However, net metering is subject to criticism from several perspectives. Existing and potential users of solar (and other renewable energy) technology argue that lowered FiT discourages sustainable PV uptake. They often raise that national gross feed in tariff programs have been established around the world, resulting in increased uptake of solar and wind power systems among home owners and businesses (FiT, 2014). In this part, a quick example case is given to prove the otherwise. We consider two Australian territories, one QLD with constant FiT of 44c for most of 2010-2012 (i.e., until July 2012), and South Australian (SA) with FiT=44c (until September 2011), which was then lowered to $\simeq 26 \mathrm{c}$ (EM, 2014). The choice of QLD and SA is due to similar initial FiTs (44c per kWh) and consistent net metering programmes in both states. However, the fact that SA changed tariff almost exactly in the middle of the 2010-2012 duration, allows for a meaningful comparison with QLD which retained tariff for the entire duration. Fig. 3 shows the summary of the consumption-generation data in QLD and SA.

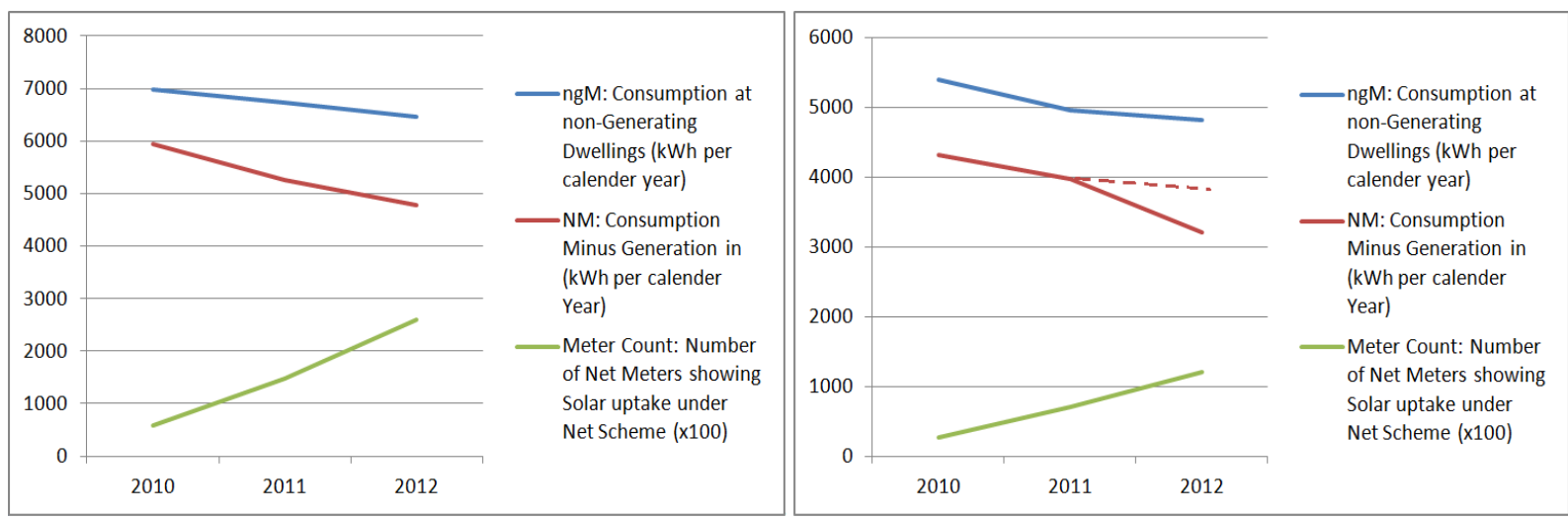

Figure 3. Annual data for NM count (green), average consumption minus generation (red), and average ngM consumption (blue), over 2010-2012 period: in Queensland (left) and in South Australia (right).

For non-generating dwellings, reduction of electricity consumption is apparent in both states, which also applies to whole country. It is proven that Australians now tend to use less electricity, mainly due to efficiency, and mindfulness. In terms of impact of FiT, Fig. 3(a) for QLD with constant FiT shows constant solar uptake rate (meter count), and constant rate of net metering (i.e., offset of consumption and generation at NM dwellings). A different situation is realised for WA in Fig. 3(b) where reduction of FiT in 2011 gives an elbow to net metering, as well as non-generating metering, however not to solar uptake rate. In other words, with or without FiT reduction, solar uptake in 2011-2012 continues to grow at the same rate as in 2010-2011 or even slightly higher. The interpretation about elbows in ngM and NM characteristics in SA is apparently due to the impact of FiT changes in 2011. It could be observed that from 2010 to 2011, the energy consumed by non-generating dwellings (blue) has the same reduction as the offset of imported and exported energy at net metering dwellings (red). The difference of about $1000 \mathrm{kWh}$ between the two curves is therefore interpreted as the average solar generation (9) provided both ngM and NM households have similar average demand for electricity. In fact, we have previously shown that generating households often tend to consume more electricity (an excess of $\mathrm{E}_{\mathrm{c}} \mathrm{kWh}$ ) compared to non-generating ones (10), i.e., a rebound effect. Fig. 3(b) is used to establish a qualitative analysis. Consumption at ngM dwellings is presumably independent from solar FiT. Given this, without any changes to FiT from 2011 to 2012, NM should have remained parallel to ngM (perforated red in Fig. 3(b)). Accordingly, the deviation of NM from ngM in 2011-2012 (i.e., to approximately $600 \mathrm{kWh}$ lower) could be interpreted as being either due to lowered NM consumption or increased NM solar generation capacity, both in response to FiT reduction. While both scenarios are favourable, the answer more likely lies in higher generation capacity (solar uptake), alongside positive rate of meter counts. The impacts of changes are rather absorbed by households in terms of consumption behaviour (lowered consumption) and increased generation capacity. It is seen that solar uptake rate has remained positively increasing despite lowered FiT. Solar investment continues to grow with or without FiT as most users find it a viable asset, not only for electricity supply, but for the environment. As described in (6), for similar annual patterns of average solar radiation and average household consumption, $J$ is supposed to remain 
constant along years and across quintiles of sample dwellings, i.e., number of hours of $g>d$. In contrast, by interpreting $J$ as solar capacity, a conclusion could be made about average panel size to increase year by year and from lower quintile to higher quintile. Individual dwellings have different $J$ value; therefore, using data of individual dwellings in this example, we infer the value of coefficient $\gamma$ to elaborate Eq. 6 to Eq. 11 .

Accordingly, with $\gamma \simeq 0.48$, average panel size is obtained 2.3 and $4.3 \mathrm{~kW}$ in 2011 and 2012, respectively. A limitation however is about duration of micro data limited to the summer months.

$n g M \equiv N M: E_{\text {in }}-1000=E_{\text {in }}-E_{\text {out }}$

$$
n g M \not \equiv N M: E_{\text {in }}+\left(E_{c}-1000\right)=E_{\text {in }}-E_{\text {out }}
$$

$S=\gamma J+\varepsilon, \gamma=0.478, \varepsilon(0,0.01)$

\section{REFERENCES}

AAP (2010). Australian Associated Press: 2000 jobs tipped to go from NSW solar cuts, Sydney Morning Herald. p.1. Retrieved 24 November 2010, from http://news.smh.com.au/breaking-news-national/2000-jobstipped-to-go-from-nsw-solar-cuts-20101104-17f06.html

ABC (2013). Rapid uptake of solar panels puts dent in electricity market, report shows, Retrieved 25 May 2014, from http://www.abc.net.au/news/2013-08-05/new-report-shows-rapid-take-up-of-solar-panels/4864954

ABS (2013). Australian Bureau of Statistics: information paper N0. 4655.0.55.002: towards the Australian environmental-economic accounts, 2013, Available online on http://www.abs.gov.au

ABS (2014b). ABS: Household Energy Consumption Survey, Australia: Summary of Results, 2012, Retrieved 9 April 2014, from http://www.abs.gov.au/AUSSTATS/abs@.nsf/DetailsPage/4670.02012?OpenDocument

ABS (2014a). ABS: Statistical Area Level 2 (SA2s), available online and Retired from http://www.abs.gov.au/websitedbs/d3310114.nsf/home/australian+statistical+geography+standard+(asgs)

ABS (2014). ABS Census 2006 and our survey 2009, retrieved on 18 July 2014, from Energy Australia, Available online on www.abs.gov.au/census

AEMO (2014). AEMO: Australian Energy Market Operator Aggregated Price and Demand (2011 - 2015), Available online on http://www.aemo.com.au/Electricity/Data/Price-and-Demand/Aggregated-Price-andDemand-Data-Files/Aggregated-Price-and-Demand-2011-to-2015

AER (2014). Australian Energy Regulator: Electricity supply to regions of the national electricity market, Available online on http://www.aer.gov/node/9778

Ambrose, M.D., James M., Law A., Osman P., White S., (2013). The Evaluation of the 5-Star Energy Efficiency Standard for Residential Buildings. CSIRO, Australia.

Andreas Poullikkas. (2013). A comparative assessment of net metering and feed in tariff schemes for residential PV systems, Sustainable Energy Technologies and Assessments, 3, 1-8.

Ausgrid (2011). Effect of small solar Photovoltaic (PV) systems on network peak demand, Retrieved 22 May 2014 from http://www.ausgrid.com.au/Common/About-us/Newsroom/Discussions/Solar-panels-and-peakdemand-research.aspx\#.U6zDoPmSwpo

Chris Greacen, Richard Plevin, Chuenchom Sangarasri Greacen. (2003). Thai power: Net metering comes to Thailand, Refocus, 4(6), 34-37.

Couture T., and Gagnon, Y. (2010). An Analysis of Feed-in-Tariff Remuneration Models: Implications for Renewable Energy Investment, Energy Policy, 38 at 955-965.

CSIRO (2013). Change and choice: The Future Grid Forum's analysis of Australia's potential electricity pathways to 2050, Retrieved 7 May 2014, from http://www.csiro.au/Organisation-Structure/Flagships/EnergyFlagship/Future-Grid-Forum-brochure.aspx

EM (2014). Energy Matters: Feed-in tariff for grid-connected solar power systems; Feed in tariffs in Australia at a glance, available online on http://www.energymatters.com.au/government-rebates/feedintariff.php

FiT (2009). An Energy Matters community initiative. Available online on http://feedintariff.com.au/

FiT (2014a). Feed-in tariff for new applicants: Proposed feed-in tariff rates for 2015, Available online http://www. energyandresources.vic.gov.au/energy/environment-and-community/victorian-feed-in-tariffschemes/new-feed-in-tariff

Trypolska, G. (2012). Feed-in tariff in Ukraine: the only driver of renewable' industry, Energy Pol., 45, 645-653.

GE (2014). Greenforce Energy: Solar PV - Gross vs Net metering in Sydney, Retrieved 3 June 2014, from http://greenforcesolar.com.au/knowledge-base/solar-pv-gross-vs-net-metering-in-sydney/

Jasper Rigter, Georgeta Vidican. (2010). Cost and optimal feed-in tariff for small scale photovoltaic systems in China, Energy Policy, 38(11), 6989-7000.

Nick Eyre. (2013). Energy saving in energy market reform the feed-in tariffs option, Energy Pol., 52, 190-198.

Nigel Martin, John Rice, The solar photovoltaic feed-in tariff scheme in New South Wales, Australia, Energy Policy, Volume 61, October 2013, Pages 697-706

RET (2014). Renewable Energy Target, Australian, Available online http://www.environment.gov.au/climatechange/renewable-energy-target-scheme

SC (2014). Solar Choice: Solar PV Price Index July 2014, available online on http://www.solarchoice.net.au/ blog/solar-power-system-prices-sydney-melbourne-perth-canberra-adelaide-july-2014

SFF (2009). Solar Flagships Forum The Hon Martin Ferguson AM MP, Available online on and retrieved from http://archive.today/3goye\#selection-521.0-521.74

Zahedi, A. (2009). Development of an economical model to determine an appropriate feed-in tariff for gridconnected solar PV electricity in all states of Australia, Renewable and Sust. Energy Rev., 13(4), 871-878. 